\title{
A Novel Solid State Dye-Sensitized Solar Cell Containing PMMA/PVDF- Type Blended Polymer Electrolyte
}

\author{
S. AMUDHA*, S. AUSTIN SUTHANTHIRARAJ and P .MARUTHAMUTHU \\ Department of Energy, University of Madras, Maraimalai Campus, Guindy, \\ Chennai-600 025, India \\ amudha.sbs@gmail.com
}

Received 24 November 2012 / Accepted 17 December 2012

\begin{abstract}
Development of nanocrystalline $\mathrm{TiO}_{2}$ dye-sensitized solar cells (DSSCs) consisting of $\mathrm{KI}$ and $\mathrm{I}_{2}$ as redox couple, phenothiazine (PTZ) as an additive dissolved in a blended solid polymer electrolytic medium of polymethylmethacrylate (PMMA) in conjunction with polyvinylidene fluoride (PVDF) has been reported. The effect of incorporation of PTZ within the PMMA/PVDF/KI/I electrolyte system has been investigated in terms of important parameters such as fill-factor (ff), shortcircuit current density $\left(\mathrm{J}_{\mathrm{sc}}\right)$, open-circuit photovoltage $\left(\mathrm{V}_{\mathrm{oc}}\right)$ and solar radiation to electrical energy conversion efficiency $(\eta)$ of the DSSC while their optimized values are found to be $0.5,5.8 \mathrm{~mA} / \mathrm{cm}^{2}$, $820 \mathrm{mV}$ and $4.8 \%$ respectively.
\end{abstract}

Keywords: Polymer electrolyte, Energy, Electrical energy and Solar Cell

\section{Introduction}

Nowadays many researchers are focusing their efforts on the development of renewable energy resources to suit present and future energy demands. Up to now, photovoltaic cells have gained much attention due to their low production costs, high energy-conversion efficiencies and environmental benignity. Silicon-based solar cells have been manufactured on a large scale, and their installation is encouraged by many nations. However, their high manufacturing costs spur the development of other types of solar cells. The concept of dyesensitized solar cells (DSSCs) is well thought-out as a low-cost alternative to traditional silicon-based cells ${ }^{1,2}$. The essential principle involved in the energy conversion of DSSCs contains injection of electrons from the excited state of dye molecules into conduction band of $\mathrm{TiO}_{2}$ semiconductor material whereas charge transport in these liquid electrolytes is accomplished by using an organic solvent containing $\mathrm{I}^{-} / \mathrm{I}_{3}^{-}$redox couple ${ }^{3}$ and these liquid electrolytes exhibit higher energy conversion efficiency of $11 \%$ as reported earlier by Gratzel in the year $1991^{1}$. The usage of liquid electrolytes accomplishes several practical problems such as solvent evaporation, electrolyte leakage, temperature instability and toxicity. However, those challenges in DSSCs, such as improving the material durability and prolonging cell lifetime, need to be resolved prior to commercialization by replacing liquid 
electrolytes by solid polymer electrolytes. Among numerous candidate polymer matrices, the most investigated include $\mathrm{PEO}^{4}, \mathrm{PVDF}^{-c o-C T F E}{ }^{5}$ and $\mathrm{PMMA}^{6}$. Today, polymer blending is a versatile and widely used method for optimizing the cost-performance balance and increasing the range of potential applications, especially for fluoropolymers such as PVDF which is often blended with amorphous polymers, among which poly (methyl methacrylate) (PMMA) has been the most studied compatible polymer owing to its low cost, optical properties, performance advantages and its nature of miscibility with other polymers in the melting state. In this endeavor, PMMA/PVDF based blended polymer electrolyte has been prepared using solution casting technique with a view to investigate the influence of phenothiazine (PTZ) and to increase the ionic mobility within the polymeric system. The inclusion of $\mathrm{PTZ}$ into PMMA/PVDF/KI/I $\mathrm{I}_{2}$ complex is expected to increase the efficiency of the dye-sensitized solar cell as well. The plasticizer phenothiazine (Thiodiphenyl amine) has only one nitrogen atom in the five-membered heterocyclic ring that could donate lone pair of electrons and it has already been demonstrated that $\mathrm{N}$-containing heterocycles may enhance the open circuit photovoltage $\mathrm{V}_{\mathrm{oc}}$ of a dye-sensitized solar cell. In general, Kusama and Arakawa ${ }^{7}$ reported that the lone pair of electrons in amine derivatives would interact with $\mathrm{I}^{-}$ $/ \mathrm{I}_{3}{ }^{-}$redox couple and also confirmed that amines auspiciously increased the short circuit current density $\left(\mathrm{J}_{\mathrm{sc}}\right)$ and open circuit voltage $\left(\mathrm{V}_{\mathrm{oc}}\right)$ of the solar cell as well. In this work, the effective interaction of phenothiazine (PTZ) on the photocurrent-voltage (I-V) characteristics of nanocrystalline $\mathrm{TiO}_{2}$ dye-sensitized solar cells (DSSCs) has been examined along with the consequential modification in terms of x-ray diffraction (XRD) measurements, Fourier transform infrared spectroscopic (FTIR) studies, complex impedance analysis and scanning electron microscopic (SEM) analyses.

\section{Experimental}

Poly (methyl methacrylate), PMMA of average molecular weight $9 \times 10^{5}$ (Aldrich) and poly (vinylidene fluoride), PVDF of molecular weight 275, 000 (Aldrich) were used as starting materials for the synthesis of blended polymer samples by solution casting method. The polyblend electrolyte samples were prepared by mixing $0.1 \mathrm{~g}$ of PMMA, $0.2 \mathrm{~g}$ of PVDF, $0.03 \mathrm{~g}$ of $\mathrm{KI}$ and $0.006 \mathrm{~g}$ of $\mathrm{I}_{2}$ in $20 \mathrm{~mL}$ of the solvent namely dimethyl formamide (DMF) and the solution was stirred at $353 \mathrm{~K}$ for $2 \mathrm{~h}$. In addition to that, different concentrations of phenothiazine (PTZ) were added into the mixture and the solution was stirred at $353 \mathrm{~K}$ for another $2 \mathrm{~h}$ until homogeneous solutions were obtained and the same were subsequently cast onto glass petri dishes and left to evaporate slowly under vacuum at $333 \mathrm{~K}$ for 1 day.

\section{Characterization of polymer electrolyte specimens}

\section{$X$-ray diffraction $(X R D)$ measurements}

The room-temperature $(298 \mathrm{~K}) \mathrm{x}$-ray diffraction $(\mathrm{XRD})$ patterns were recorded for all those thin film samples of the blended polymer electrolyte system PMMA/PVDF/KI/I $/ 2 /(\mathrm{z}) \mathrm{g} \mathrm{PTZ}$ (where $\mathrm{z}=0,0.004,0.009,0.014,0.019,0.024,0.029$ and 0.034 respectively) using a Bruker D8 Advance x-ray diffractometer with $\mathrm{CuK} \alpha$ as the radiation source $(\lambda=1.541 \AA)$ operated at $40 \mathrm{kV}$ and $30 \mathrm{~mA}$ over the scanning angle range $10-40^{\circ}(2 \theta)$ and at the scanning rate of $0.05 \% \mathrm{~min}$.

\section{Fourier transform infrared (FTIR) measurements}

Fourier transform infrared spectroscopy has been used to characterize the molecular interaction occurring between plasticizer and chain structure of polymer electrolytes. The complexation of PMMA/ PVDF blended polymer electrolyte with phenothiazine (PTZ) has 
been examined by the FTIR spectra recorded using a FTIR Spectrophotometer (Bruker, Tensor 27), at the wave number resolution of $1 \mathrm{~cm}^{-1}$ and with a total number of scans as 32 in the range $4000-400 \mathrm{~cm}^{-1}$ on the transmittance mode.

\section{Complex impedance studies}

Electrical conductivity measurements were performed using a computer-interfaced HewlettPackard Model HP4284A Precision LCR Meter at room temperature (298 K) in the frequency domain $20 \mathrm{~Hz}-1 \mathrm{MHz}$ by complex impedance analysis. The impedance data obtained in the form of impedance diagrams (i.e., plots of Z' vs. Z' where Z' and Z' represent real and imaginary parts of impedance, respectively) were analyzed by means of Boukamp equivalent circuit program software available internally during each measurement as reported elsewhere ${ }^{8}$. During such measurements thin film specimens were sandwiched between two silver discs and the electrical conductivity $(\sigma)$ of various polymer electrolyte samples were determined using the relationship where $t$ is the thickness of the polymer electrolyte film, $R_{b}$ the bulk resistance and $A$ is the cross-sectional area of the film membrane . $^{8}$

$$
\sigma=\frac{t}{A \cdot R_{b}}
$$

\section{Scanning electron microscopic (SEM) studies}

Micrographs of undoped PMMA/PVDF/KI/I 2 and doped PMMA/PVDF/KI// $/ 2 / 0.004 \mathrm{PTZ}$ samples were acquired using a Hitachi-S 3400N Model scanning electron microscope with an accelerating voltage of $15 \mathrm{kV}$. The cross section was obtained by fracturing the sample in liquid nitrogen and it was then vacuum-dried, coated with gold particles and attached to a sample holder with the help of conductive copper tapes.

\section{Fabrication and characterization of dye-sensitized solar cells (DSSCs)}

A nanocrystalline $\mathrm{TiO}_{2}$ photoelectrode was prepared as previously described ${ }^{9}$. The dye was adsorbed on the $\mathrm{TiO}_{2}$ photoanode by immersing the $\mathrm{TiO}_{2}$ photoelectrode in a solution of [Cis-di(thiocyanato)- $N, N$-bis (2,2'-bipyridyl-4,4'-dicarboxylic acid) ruthenium (II)] dihydrate (N3 dye) of $5 \times 10^{-5}$ mole concentration in absolute ethanol for $24 \mathrm{~h}$ at $298 \mathrm{~K}$ and washed again with absolute ethanol and dried in a moisture-free atmosphere. The $\mathrm{TiO}_{2}$ photoelectrode was washed, dried and instantaneously used to estimate the solar cell performance. Finally, the homogeneous blended polymer electrolyte solution was dropped onto the dyeadsorbed $\mathrm{TiO}_{2}$ electrodes and the solvent was eliminated using a hot plate. A prototype photoelectrochemical cell was constructed with the following configuration: $\mathrm{TiO}_{2} / \mathrm{N} 3$ dye/PMMA/PVDF/KI/I $2 / \mathrm{PTZ} / \mathrm{Pt}$

Current-Voltage (I-V) characteristics of the of dye-sensitized solar cells (DSSCs) were evaluated by using a solar light simulator (OSRAM Germany) as the light source and BAS $100 \mathrm{~A}$ Electrochemical analyzer as the current-voltage recorder which provided AM 1.5 illumination at an effective light intensity of $50 \mathrm{~mW} / \mathrm{cm}^{2}$.

\section{Results and Discussion}

\section{$X$-ray diffraction $(X R D)$ results}

Figure 1 shows the $\mathrm{X}$-ray diffraction patterns acquired for thin film specimens of blended solid polymer electrolyte samples of various compositions of the system namely PMMA/PVDF/KI/I $/ 2$ (z) g PTZ (where $\mathrm{z}=0,0.004,0.009,0.014,0.019,0.024,0.029$ and 0.034 respectively). The diffraction peaks observed at $2 \theta=20.5^{\circ}$ and $26.6^{\circ}$ correspond to 
[110] and [021] reflection planes of crystalline $\mathrm{PVDF}^{10}$. It is therefore apparent that the crystallinity of the thin film blended polymer electrolyte specimen has been extensively decreased as a result of incorporation of phenothiazine (PTZ) into PMMA/PVDF-based blended polymer complexes whereas the peak corresponding to $2 \theta=26.6^{\circ}$ is shifted to 25 , 25.1, 25.3, 25.5, 25.2, 25.2 and 25.3 for those complexes having $\mathrm{z}=0.004,0.009,0.014$, $0.019,0.024,0.029$ and 0.034 respectively. In addition, several other low intensity peaks equivalent to other crystalline phases of blended polymer electrolyte have also been observed for those samples containing higher concentrations of phenothiazine (PTZ). The intensity of the peak corresponding to $2 \theta=20.5^{\circ}$ is greatly reduced for the sample containing $\mathrm{z}=0.004$ as evidenced from Figure 1 and this feature indicates the complete dissolution of phenothiazine (PTZ) into the PMMA/PVDF/KI/I $\mathrm{I}_{2}$ polymer matrix. This sort of shifting of peaks and corresponding decrease in the relative intensities of the peaks tend to show that the complete dissolution has taken place between PMMA/PVDF polymer and plasticizer PTZ. These results may be inferred by Hodge et $a l^{11}$ criterion which ascertains a connection between the relative intensity of the peak and degree of crystallinity. The experientially observed decrease in intensity may be due to the molecular interaction of PTZ with the structural organization within PMMA/PVDF blended polymer electrolyte and as the amorphous nature increases the ionic mobility is expected to increase as supported by the present conductivity results too ${ }^{11}$. On the whole, the present XRD results have clearly shown that the doped blended polymer electrolyte exhibits diminution in crystallinity and forms a charge transfer complex with the $\mathrm{I}^{-} / \mathrm{I}_{3}^{-}$redox couple which in turn may improve the performance of the dye sensitized solar cell.

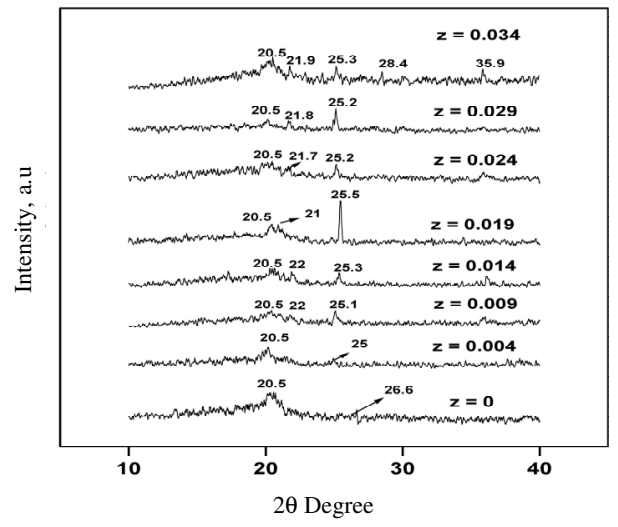

Figure 1. X-ray diffraction patterns obtained for PMMA/PVDF/KI/I $/ 2 /(\mathrm{z}) \mathrm{g}$ PTZ blended polymer electrolyte system where $0 \leq \mathrm{z} \leq 0.034$

\section{FTIR spectroscopic results}

The fourier transform infrared (FTIR) spectra obtained for various compositions of the blended polymer electrolyte samples of PMMA/PVDF/KI/I $/(\mathrm{z}) \mathrm{g} \mathrm{PTZ} \mathrm{(where} \mathrm{z}=0,0.004$, $0.009,0.014,0.019,0.024,0.029$ and 0.034 respectively) in the wavenumber region 4000 $400 \mathrm{~cm}^{-1}$ are shown in Figure 2.

From the above figure it is evident that the characteristic vibrational peak observed at $3473 \mathrm{~cm}^{-1}$ in the case of PTZ-doped blended polymer electrolyte indicates the existence of the $\mathrm{N}-\mathrm{H}$ group due to the outlook that the solvent DMF is basically a tertiary amide and therefore it is clear that the tertiary amide does not show any peak in the region $3500-3100 \mathrm{~cm}^{-1}$. 


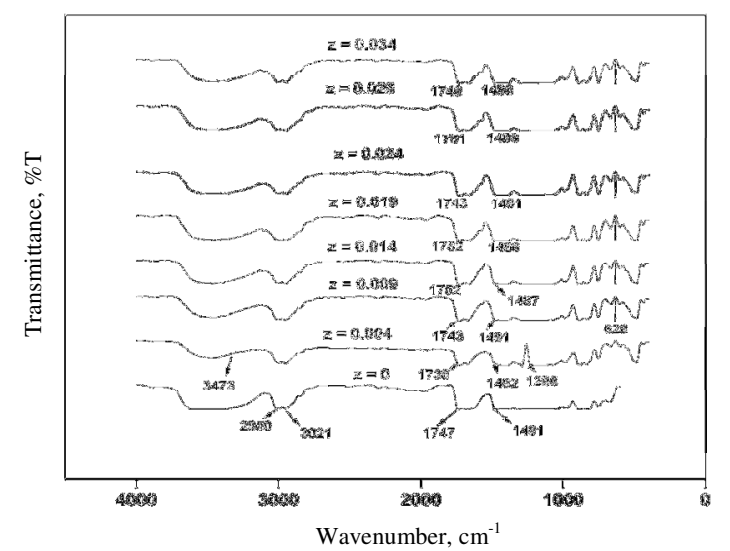

Figure 2. FTIR spectra obtained for the system PMMA/PVDF/KI/I $/ 2 /(z)$ g PTZ where $0 \leq \mathrm{z}$ $\leq 0.034$

The occurrence of vibrational frequencies at 3021 and $2950 \mathrm{~cm}^{-1}$ corresponds to $\mathrm{C}-\mathrm{H}$ stretching vibration of $\mathrm{PVDF}^{13}$ and $\mathrm{O}-\mathrm{CH}_{2}$ asymmetric stretching vibration of $\mathrm{PMMA}^{14}$. The vibrational stretching frequency materializing originally at $1730 \mathrm{~cm}^{-1}$ corresponding to $\mathrm{O}-\mathrm{CH}_{3}$ deformation vibration of pure PMMA as reported earlier ${ }^{15}$ is shifted towards 1747 , $1738,1743,1752,1752,1743,1751$ and $1748 \mathrm{~cm}^{-1}$ in the case of PMMA/PVDF/KI/I $\left./ 2 \mathrm{z}\right) \mathrm{g}$ PTZ blended polymer electrolyte samples having $\mathrm{z}=0,0.004,0.009,0.014,0.019,0.024$, 0.029 and 0.034 respectively. The fact that the nature of shift observed in the case of PMMA/PVDF/KI/I $/$ /(z) g PTZ complex may be attributed to the interaction occurring between carbonyl carbon atoms of PMMA and fluorine atoms of PVDF signifies the creation of a well defined complex. This aspect is found to be in excellent conformity with those results reported by Colemann et al. ${ }^{16}$ in the case of PMMA/PVDF binary blends. The characteristic vibrational frequency appearing at $1287 \mathrm{~cm}^{-1}$ corresponding to C-F stretching vibration of $\mathrm{PVDF}^{10}$ is shifted to $1286 \mathrm{~cm}^{-1}$ for the typical sample containing $\mathrm{z}=0.004$ in $\mathrm{PMMA} / \mathrm{PVDF} / \mathrm{KI} / \mathrm{I}_{2} /(\mathrm{z})$ g PTZ complexes and it gets diminished for the remaining complexes whereas the sharp and intense absorption peak observed at $638 \mathrm{~cm}^{-1}$ may be due to amorphous nature of PMMA polymer ${ }^{17}$. The vibrational frequency appearing at $1483 \mathrm{~cm}^{-}$ ${ }^{1}$ corresponding to $\mathrm{CH}_{2}$ scissoring of PMMA as reported earlier ${ }^{17}$ is shifted to 1491,1482 , 1491, 1487, 1496, 1491, 1496 and $1496 \mathrm{~cm}^{-1}$ for those samples containing $\mathrm{z}=0,0.004$, $0.009,0.014,0.019,0.024,0.029$ and 0.034 . This type of shifting of vibrational band may be attributed to the specific interaction taking place between fluorine atoms of PVDF and carbon molecule connected to oxygen atom of PMMA which may act as a Lewis base and a Lewis acid respectively.

\section{Electrical conductivity results}

Figures $3 \mathrm{a}$ and $3 \mathrm{~b}$ show the set of complex impedance plots obtained for PMMA/PVDF/KI/ $\mathrm{I}_{2} /(\mathrm{z}) \mathrm{g}$ PTZ (where $\mathrm{z}=0,0.004,0.009,0.014,0.019,0.024,0.029$ and 0.034 respectively) thin film blended polymer electrolyte systems at room temperature $\left(\sigma_{298 \mathrm{~K}}\right)$. The electrical conductivity data obtained for $\mathrm{PMMA} / \mathrm{PVDF} / \mathrm{KI} / \mathrm{I}_{2} /(\mathrm{z}) \mathrm{g}$ PTZ polymer electrolyte system are presented in Table 1. From Table 1 it is seen that the undoped PMMA/PVDF/KI/I $/ 2$ shows the conductivity value of $4.5 \times 10^{-7} \mathrm{~S} \mathrm{~cm}^{-1}$ and as a result of incorporation of $0.004 \mathrm{PTZ}$ into $\mathrm{PMMA} / \mathrm{PVDF} / \mathrm{KI} / \mathrm{I}_{2}$ complex it shows a maximum electrical conductivity of $4.5 \times 10^{-6} \mathrm{~S} \mathrm{~cm}^{-1}$ 
which may result due to an enhancement of amorphous nature of the polymeric complex PMMA/PVDF. Furthermore, it is also observed that as the concentration of PTZ increases the ionic conductivity increases up to $\mathrm{z}=0.004$ and afterwards it decreases. Therefore, it is clear that PTZ plays a vital role in improving the ionic conductivity of the polymer electrolyte thereby enhancing the mobility of the polymer chain. Generally, ionic mobility is associated with the free volume and as the plasticizer PTZ is introduced into the $\mathrm{PMMA} / \mathrm{PVDF} / \mathrm{KI} / \mathrm{I}_{2}$ complex the free volume of the polymer electrolyte increases resulting in an increase in ionic conductivity ${ }^{18}$. The incorporation of an organic nitrogenous compound PTZ as a plasticizer into the polymer matrix could be attributed to form a charge transfer complex with iodine thereby reducing the sublimation of iodine and hence enhance the conductivity as well as solar energy to electrical energy conversion efficiency.
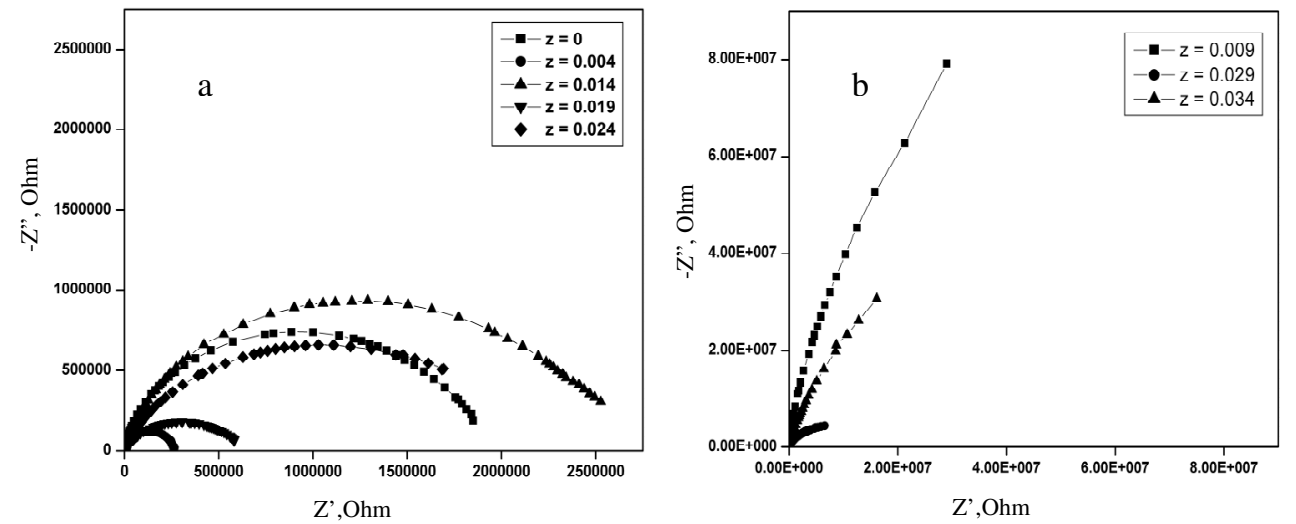

Figure 3. Complex impedance plots obtained for the system PMMA/PVDF/KI/I $/(\mathrm{z}) \mathrm{g} \mathrm{PTZ}$ where $0 \leq \mathrm{z} \leq 0.034$

Table 1. Room temperature electrical conductivity $\left(\sigma_{298}\right)$ values observed for the PMMA/ $\mathrm{PVDF} / \mathrm{KI} / \mathrm{I}_{2} /$ (z) g PTZ blended polymer electrolyte system where $0 \leq \mathrm{z} \leq 0.034$

\begin{tabular}{cc}
\hline Composition, $\mathrm{g}$ & Room temperature electrical conductivity $\sigma_{298 \mathrm{~K}}, \mathrm{Scm}^{-1}$ \\
\hline $\mathrm{z}=0$ & $4.5 \times 10$ \\
$\mathrm{z}=0.004$ & $4.5 \times 10$ \\
$\mathrm{z}=0.009$ & $5.1 \times 10$ \\
$\mathrm{z}=0.014$ & $5.7 \times 10$ \\
$\mathrm{z}=0.019$ & $3.2 \times 10$ \\
$\mathrm{z}=0.024$ & $7.6 \times 10$ \\
$\mathrm{z}=0.029$ & $1.1 \times 10$ \\
$\mathrm{z}=0.034$ & $1.4 \times 10$ \\
\hline
\end{tabular}

\section{SEM results}

The microscopic investigation of the cross section of undoped PMMA/PVDF/KI/I 2 and doped PMMA/PVDF/KI/ $/ \mathrm{I}_{2} / 0.004 \mathrm{PTZ}$ thin film blended polymer electrolyte specimens are shown in Figures $4 \mathrm{a}$ and $4 \mathrm{~b}$ respectively. The SEM image for PMMA/PVDF/KI/I 2 shows a compact and rough structure with the collection of very small particles closely bound to each other along with different spherulitic structures whereas in the case of optimized PMMA/ $\mathrm{PVDF} / \mathrm{KI} / \mathrm{I}_{2} / 0.004 \mathrm{PTZ}$ blended polymer electrolyte system the microstructure appears to be 
smoother with the disappearance of spherulites and more compact thus indicating that the film is quite dense and homogeneous. In addition to this, the repeating unit $-\left(\mathrm{CH}_{2}-\mathrm{CF}_{2}\right)_{n}-$ in PVDF molecule seems to present a favorable arrangement for effective interaction of the free electron pairs of fluorine with alkali metal cation in PTZ. In fact, it was observed that the presence of $\mathrm{K}^{+}$cations influences the mobility of the PVDF molecule along with PMMA side chains thus demonstrating favorable polymer chain-cation interactions. Such a condition could only be obtained when the polymer is in its amorphous state. SEM investigation strongly supports this conclusion showing that the undoped PMMA/ $\mathrm{PVDF} / \mathrm{KI} / \mathrm{I}_{2}$ blended polymer electrolyte sample has a crystalline morphology with a compact and well-connected structure whereas doped PMMA/PVDF/KI $/ \mathrm{I}_{2} / 0.004 \mathrm{PTZ}$ shows the interaction between PMMA, PVDF, KI, $\mathrm{I}_{2}$ and PTZ without spherulites and semicrystalline morphology.
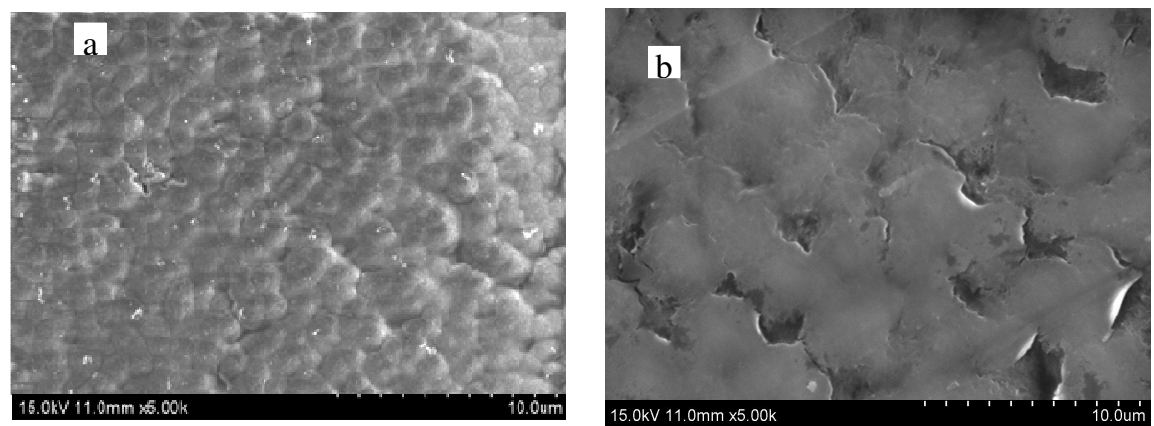

Figure 4. SEM image obtained for a. PMMA/PVDF/KI/I $\mathrm{I}_{2}$ and b. PMMA/PVDF/KI $/ \mathrm{I}_{2} / 0.004$ g PTZ blended polymer electrolyte system

\section{Characteristics of photovoltaic cells}

The current-voltage (I-V) characteristics of innovatively formulated dye sensitized solar cells (DSSCs) having different concentrations of the dopant viz., PTZ in PMMA/ PVDF/KI/I blended polymer electrolyte system are shown in Figure 5 and the corresponding photovoltaic parameters evaluated for cells based on PMMA/PVDF/KI $/ \mathrm{I}_{2} /(\mathrm{z}) \mathrm{g}$ PTZ (where $\mathrm{z}=0,0.004$, $0.009,0.014,0.019,0.024,0.029$ and 0.034 respectively) polymer electrolyte systems are summarized in Table 2. These data show that the typical device based on PMMA/PVDF $/ \mathrm{KI} / \mathrm{I}_{2} / 0.004 \mathrm{~g}$ PTZ electrolyte exhibits the best performance with highest values of shortcircuit current density $\left(\mathrm{J}_{\mathrm{sc}}\right)$, open-circuit voltage $\left(\mathrm{V}_{\mathrm{oc}}\right)$, fill factor (ff) and photoelectric energy conversion efficiency $(\eta)$ among chosen polymer electrolyte systems. Here, the lone pair of electrons in phenothiazine (PTZ) is likely to easily interact with $\mathrm{I}^{-} / \mathrm{I}_{3}{ }^{-}$redox couple and prevent the sublimation of $\mathrm{I}_{2}$ to a considerable extent which may in turn increase the short-circuit current density $\left(\mathrm{J}_{\mathrm{sc}}\right)$ and open-circuit voltage $\left(\mathrm{V}_{\mathrm{oc}}\right)$ values of the dye-sensitized solar cell ${ }^{19}$. It is interesting to note that a correlation has taken place between $V_{\text {oc }}$ value and energy of the HOMO level of the lone pair of electrons which may be explained in terms of probable interaction between HOMO of donors and LUMO of acceptors on the basis of the theory of intermolecular charge transfer complexes ${ }^{20}$ specifically between phenothiazine and $\mathrm{I}^{-} / \mathrm{I}_{3}{ }^{-}$redox couple. Therefore, it may be easier to form a charge-transfer complex with iodine and owing to donor-acceptor correlations occurring between PTZ and $\mathrm{I}^{-} / \mathrm{I}_{3}{ }^{-}$redox couple thereby enhancing the efficiency of nanocrystalline $\mathrm{TiO}_{2}$ dye-sensitized solar cells (DSSCs) and yielding an overall energy conversion efficiency of $4.8 \%$ at AM 1.5 solar irradiation. 


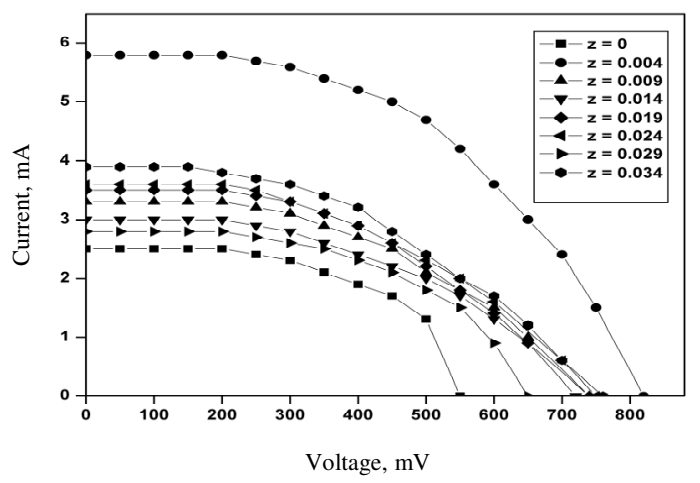

Figure 5. Current density-voltage (I-V) curves obtained for dye-sensitized solar cell having the PMMA/PVDF/KI/I $/ 2$ (z) g PTZ blended polymer electrolyte system where $0 \leq \mathrm{z} \leq 0.034$

Table 2. Photovoltaic parameters evaluated for dye-sensitized solar cells having the blended polymer electrolyte system PMMA/PVDF/KI// $/ 2$ (z) g PTZ where $(0 \leq \mathrm{z} \leq 0.034)$

\begin{tabular}{ccccc}
\hline $\begin{array}{c}\text { Composition, } \\
\mathrm{g}\end{array}$ & $\begin{array}{c}\text { Short-circuit current } \\
\text { density } \mathrm{J}_{\mathrm{sc}}, \mathrm{mA} / \mathrm{cm}^{2}\end{array}$ & $\begin{array}{c}\text { Open-circuit } \\
\text { voltage } \mathrm{V}_{\mathrm{oc}}, \mathrm{mV}\end{array}$ & $\begin{array}{c}\text { Fill } \\
\text { factor, ff }\end{array}$ & $\begin{array}{c}\text { Efficiency } \\
\eta, \%\end{array}$ \\
\hline $\mathrm{z}=0$ & 2.5 & 550 & 0.48 & 1.4 \\
$\mathrm{z}=0.004$ & 5.8 & 820 & 0.5 & 4.8 \\
$\mathrm{z}=0.009$ & 3.3 & 740 & 0.48 & 2.3 \\
$\mathrm{z}=0.014$ & 3 & 720 & 0.48 & 2.1 \\
$\mathrm{z}=0.019$ & 3.5 & 740 & 0.44 & 2.3 \\
$\mathrm{z}=0.024$ & 3.6 & 750 & 0.42 & 2.2 \\
$\mathrm{z}=0.029$ & 2.8 & 650 & 0.49 & 1.8 \\
$\mathrm{z}=0.034$ & 3.9 & 760 & 0.4 & 2.4 \\
\hline
\end{tabular}

\section{Conclusion}

Thin films of PMMA/PVDF/KI/I $\mathrm{I}_{2}$ polyblend electrolyte systems consisting of various concentrations of PTZ were prepared by solution casting technique and characterized by XRD, FTIR, electrical conductivity, DSC, SEM and photovoltaic studies. XRD and FTIR studies have revealed the coordinative interaction and miscibility of PMMA/PVDF blends with PTZ whereas SEM analysis has illustrated that the structure of doped PMMA/PVDF/KI $/ \mathrm{I}_{2} / 0.004 \mathrm{PTZ}$ would lead to a drastic change when compared to undoped PMMA/PVDF/KI/I 2 . The electrical conductivity results show a maximum room temperature ionic conductivity value of $4.5 \times 10^{-6} \mathrm{Scm}^{-1}$ whereas an increase in the conductivity due to the possible interaction between $\mathrm{K}^{+}$metal cation and lone pair of nitrogen molecule present within the doped polymer electrolyte leading to the formation of $\mathrm{I}^{-} / \mathrm{I}_{3}{ }^{-}$redox couple has also been noticed. Efficient dye-sensitized solar cells (DSSCs) have been fabricated and the favorable influence of PTZ on the performance of PMMA/PVDF/KI/ $\mathrm{I}_{2}$ blended polymer electrolyte in nanocrystalline dye-sensitized solar cells has been demonstrated.

\section{References}

1. O'Regan B and Gratzel M, Nature, 1991, 353, 737-740.

2. Yanagida S C R, Chim., 2006, 9, 597-604.

3. Kim J H, Kang M S, Kim Y J, Won J, Park N G and Kang Y S, Chem Commun., 2004, 1662-1663. 
4. Paruthimal Kalaignan G, Kang M S and Kang Y S, Solid State Ionics, 2006, 177, 1091-1097.

5. Seo J A, Roh D K, Yeon S H, Byun S J and Kim J H, Current Appl Phys., 2010, 10(3), S414-S417.

6. $\quad$ Song J Y, Wang Y Y and Wan C C, J Power Sources, 1999, 77, 183-197.

7. Kusama H and Arakawa H, Sol Energy Mater Sol Cells., 2004, 81(1), 87-99.

8. Suthanthiraraj S A and Sheeba D J, Ionics, 2007, 13(6), 447-450.

9. Anthonysamy A, Balasubramanian S, Muthuraaman B and Maruthamuthu P, Nanotechnology, 2007, 18, 95701.

10. Saikia D and Kumar A, Euro Polym J., 2005, 41, 563-568.

11. Mahendran O, Chen S Y, Chen-Yang Y W, Lee J Y and Rajendran S, Ionics, 2005, 11, 251-258.

12. Patania V B, Spectroscopy, Campus Books International, New Delhi, 2002, 134.

13. Saikia D and Kumar A, Electrochim Acta, 2004, 49, 2581-2589.

14. Rajendran S, Shanthi Bama V and Ramesh Prabhu M, Ionics, 2010, 16(3), 283-287.

15. Osman Z, Ansor N M, Chew K W and Kamarulzaman N, Ionics, 2005, 11, 431.

16. Colemann M M, Zarian J, Varnel D F and Painter P C, J Polym Sci Polym Lett., 1977, 15, 745 .

17. Rajendran S, Mahendran O and Kannan R, Fuel, 2002, 81(8), 1077-1081.

18. Rajendran S, Mahendran O and Mahalingam T, Euro Polym J., 2002, 38, 49.

19. He J, Benko G, Korodi, Polivka T, Lomath R, Akermark B, Sur L, Hagfeldt A and Sundststrom V, J Am Chem Soc., 2002, 124, 4922-4932.

20. Kusama H, Arakawa H and Sugihara H, J Photochem Photobiol A Chem., 2005, 171(2), 197-204. 